\title{
A Sample of The Relationship Between The Non- Integrated Healthcare System And National Epidemic of Emergency Department Overcrowding In Turkey
}

Cihad Dundar ( $\square$ cdundar@omu.edu.tr)

Ondokuz Mayis University Faculty of Medicine: Ondokuz Mayis Universitesi Tip Fakultesi https://orcid.org/0000-0001-9658-2540

Seydanur Dal Yaylaoglu

Ondokuz Mayis University Faculty of Medicine: Ondokuz Mayis Universitesi Tip Fakultesi

\section{Research}

Keywords: Emergency department use, hospital, integrated care, non-urgent visit

Posted Date: August 31st, 2021

DOl: https://doi.org/10.21203/rs.3.rs-818815/v1

License: (c) (i) This work is licensed under a Creative Commons Attribution 4.0 International License.

Read Full License 


\section{Abstract}

Background: The use of EDs has significantly increased, and a majority of this increase is attributed to non-urgent visits, which has negative impacts. We aim to explore the frequency of non-urgent emergency department (ED) visits and to identify risk factors for non-urgent ED visits.

Methods: This retrospective, the record-based study was conducted at a tertiary hospital in Samsun province of Turkey. The records of all adult patients who visited to the ED between January 1 and December 31, 2017, were included in this study. All emergency department visits were evaluated according to age, gender, time of visit, means of arrival, ICD diagnostic codes, and the number of repeated non-urgent ED visits. The number of ED visits was 87,528 for the year 2017.

Results: The non-urgent emergency visit rate was $9.9 \%$. According to binary logistic analysis, non-urgent visits were associated with young age $(O R=2.75)$, female gender $(O R=1.11)$ and non-ambulance transportation $(O R=9.86)$. The prevalence of non-emergent visits was very similar between weekends and weekdays but was significantly higher in work hours on weekdays than non-work hours $(p<0.001)$. The most frequent diagnostic code was "Pain, unspecified" (R52) and the rate of repeated visits was $14.8 \%$ of non-urgent ED visits.

Conclusions: Harmonization of various databases at the primary level in terms of design and connectivity and integration with hospital information systems will contribute to the identification of problems and the generation of solutions. The next step is establishing an integrated health care system that can benefit emergency care organizations in Turkey.

\section{Background}

The use of EDs has significantly increased in developed countries, and a majority of this increase is attributed to non-urgent visits, which has negative impacts on the quality of care (1). Crowding caused by non-urgent patients prevents real emergency patients from receiving care, and the ability for emergency services to be ready for any situation, increases waiting times, the workload on personnel, and expenses (2). Inappropriate use can be considered the emergency visit of patients who do not develop accident or injury, do not require emergency treatment, and can be safely treated in primary health care institutions (3). These visits have been described with different terms, such as "inappropriate ED visits" or "avoidable ED visits", and various definitions exist, ranging from assigned triage category to self-perceived urgency $(4,5)$. In contrast, the yearly rate of emergency department visits per person is 0.43 in the USA $(6), 0.39$ in England (7), 0.31 in Australia, and 1.31 in Turkey (8).

One of the most significant reforms in Turkey in 2008 was to provide free emergency department visits to everyone regardless of their insurance status. This policy change rapidly increased the average number of visits to emergency rooms in hospitals (8). The patients can present to a hospital or ED, despite not being referred by a doctor in Turkey because the requirement for citizens to make their first visit to family health centers (FHC) or other primary official healthcare institutions was suspended in 2009 when the 
gatekeeper system was abolished (9). After the system change, while the annual number of hospital visits increased from 3.8 per person to 6.1 , hospital visits accounted for $76 \%$ of all healthcare visits between 2008 and 2010 (10). In 2017, the number of emergency department visits in Turkey rose to 101.5 million (11). This number holds value because of being higher than the total population of 80.8 million (10).

WHO recommends establishing an integrated care organization with a coherent set of methods and models on the funding, administrative, organizational, service delivery, and clinical levels designed to create connectivity, alignment, and collaboration for more effective and efficient healthcare delivery (12). These methods and models aim to enhance the quality of care and quality of life, consumer satisfaction, and system efficiency by cutting across multiple services, providers, and settings. Unfortunately integrated care system is not available in Turkey.

In this study, we aimed to determine the frequency of non-urgent emergency department visits in the Health Practice and Research Center (HPRC) of Ondokuz Mayis University and discuss the deficiencies in the health care system in Turkey through this sample.

\section{Methods}

This retrospective, a record-based study was conducted at a tertiary university hospital in Samsun, a province with a population of 1,312,990, located in the central Black Sea region of Turkey (10). The health services in this city are qualitatively similar to those provided in other cities in Turkey.

\section{Data collection}

The records of every patient over 18 years of age who visit the ED of HPRC between January 1, 2017, and December 31,2017 , were included in this study $(n=87,528)$. Data collection and pre-analysis were performed between March 1, 2018, and June 15, 2018. Routinely collected patient data were anonymized before analysis. All emergency department visits were evaluated according to age, gender, time of visit, means of arrival, ICD diagnostic codes, and the number of repeated non-urgent visits.

\section{Definition of non-urgent visit}

In all hospitals in Turkey, patients undergo effective triage performed by a physician. According to a circular issued by the Republic of Turkey Ministry of Health, as a result of the examinations conducted in the emergency services, the patients who are stable in terms of their general condition and can wait for 1-4 hours to be seen in a waiting room and not pose morbidity or life-threatening due to waiting are defined as "green zone patients". All patients documented as green zone patients following examination were considered to be non-urgent ED visits.

\section{Statistical Analysis}


Data were analyzed using the SPSS 22.0 software program (SPSS Inc., Chicago, IL, USA). Proportional differences between groups for each variable were compared using the Chi-square test. The value of $p<$ 0.05 was considered statistically significant. Binary logistic regression analysis was used to define the impact of individual risk factors on non-urgent visits. The value of $p<0.05$ was considered statistically significant.

\section{Results}

For the year $2017,78,903(90.1 \%)$ of the 87,528 visits to HPR ED were emergencies, while 8,625 (9.9\%) were non-urgencies. The median age of the non-urgent ED visit group was 30 years (range: 18-97) and 39 years in the emergency visit group (range: 18-100). As displayed in Table 1, the rate of non-urgent visits was significantly higher in females, the age group of $18-44$, and those who arrived without an ambulance. The prevalence of non-urgent visits was very similar between weekends and weekdays but was significantly higher in work hours than non-work hours on weekdays $(p<0.001)$.

\section{Table 1. Some characteristics of ED visitors by the level of emergency.}


Characteristics

Non-urgent Urgent

$\mathbf{N}(\%) \quad \mathrm{N}(\%) \quad$ Total

Gender

$\begin{array}{lllll}\text { Male } & 4110(47.7) & 36522(46.3) & 4063246896 & \mathbf{0 . 0 1 5} \\ \text { Female } & 4515(52.3) & 42381(53.7) & & \end{array}$

Nationality

Turkish

$8516(98.7) \quad 78032((98.9) \quad 86548 \quad 0.18$

$\begin{array}{llll}\text { Foreign } & 109(1.3) & 871(1.1) \quad 980\end{array}$

Age groups (year)

$18-44$

$6352(73.6) \quad 46586(59.0) \quad 52938$

$<0.001$

$45-64$

$1655(19.2)$

$19342(24.5)$

20997

$>65$

$618(7.2)$

$12975(16.5)$

13593

\section{Arrival to ED}

By own

8585 (99.5)

75055 (95.1)

83640

$<0.001$

Ambulance

$40(0.5)$

3848 (4.9)

3888

Visit day

Weekdays

$6250(725)$

57341 (72.7)

63591

0.69

Weekends

$2375(27.5)$

$21562(27.3)$

23937

Visit hours on weekdays

Work hour

Non-work hour

Total
3145 (50.3)

3105 (49.7)

$8625(100.0)$
$27379(47.7)$

30524

$29962(52.3) \quad 33067$

78903 (100.0)

87528

As a result of logistic regression analysis, young age $(\mathrm{OR}=0.98 ; \mathrm{Cl}=0.978-0.980)$, female gender $(\mathrm{OR}=$ $1.12 ; \mathrm{Cl}=1.073-1.174)$ and non-ambulance transportation $(\mathrm{OR}=9.75 ; \mathrm{Cl}=7129-13.324)$ was found to be related with non-urgent ED visit statistically significant $(p<0.001)$.

The most frequent non-urgent visits occurred in autumn and on Mondays, Wednesdays, and Tuesdays. While weekday and seasonal distributions were similar in emergent and non-urgent visits, there were differences according to month.

When the initial visits of the patients who had repeated non-urgent ED visits during the year were excluded from the evaluation, 1275 repeated ED visits were identified, which accounted for $14.8 \%$ of all 
green zone visits.

Some patients had more than one diagnostic code, as 10,037 diagnostic codes were observed in 8,625 non-urgent ED visits. The most frequent diagnostic code was "Pain, unspecified" (R52) (Table 2).

Table 2

Distribution of ICD codes of patients who visited the ED.

\begin{tabular}{|lll|}
\hline & Non-urgent & Urgent \\
\hline ICD code & N (\%) & N (\%) \\
\hline R52. Pain, unspecified & 3356 & 24062 \\
\hline J39.9. Disease of upper respiratory tract, unspecified & $(33.4)$ & $(30.4)$ \\
\hline M79. Other and unspecified soft tissue disorders, not elsewhere & 1865 & $7409(9.3)$ \\
classified & $(18.7)$ & \\
\hline R10.9. Unspecified abdominal pain & $281(2.8)$ & $1602(2.0)$ \\
\hline R07.0. Pain in throat & $254(2.5)$ & $2130(2.7)$ \\
\hline R05. Cough & $234(2.3)$ & $1149(1.5)$ \\
\hline R51. Headache & $217(2.2)$ & $1900(1.4)$ \\
\hline R11. Nausea and vomiting & $208(2.1)$ & $3860(4.9)$ \\
\hline H10. Conjunctivitis & $175(1.7)$ & $1998(5.1)$ \\
\hline M54.5. Low back pain & $133(1.3)$ & $268(0.3)$ \\
\hline Other & $112(1.1)$ & $1362(1.7)$ \\
\hline
\end{tabular}

\section{Discussion}

In our study, the non-urgent visit rate was found as $9.9 \%$. Various studies report rates ranging from $4.8-$ $90.0 \%$, as the definition of non-urgent or inappropriate emergency room visits differs worldwide $(1,13$, 14). In addition to those patients in critical condition, patients who should usually be treated in ambulatory tend to go to emergency services to accelerate their treatment process (15). Certain hospitallevel factors such as the availability of acute beds and emergency department admission procedures have been shown to drive geographical variation in potentially avoidable emergency department visits (16).

According to the per capita ED acceptance rate (1.31 per person) in Turkey, the total ED visit number is expected to be 1,720,017 annually in Samsun. Thus, there would be expected roughly 63,704 ED visits per hospital in 2017. However, as determined in this study, the number of visits to ED of HPRC (total of child 
and adult ED) was 124,871. Despite fifteen hospitals in the city center, it is considered that the number of ED visits in HPRC that is $17 \mathrm{~km}$ away from centrum is very high. There are no incentives for the care layers (primary-secondary and tertiary) to work together in Turkey. The pay system for performance in hospitals has created competition between the levels of care (17). Care coordination is a foundational element of an effective and efficient integrated care delivery system involved in a patient's care to facilitate the appropriate delivery of health care services (18). The essential element of integrated care and transition between the care layers is the reinforced primary care, particularly critical for patients with complex or urgent needs (12). Therefore, effective care requires establishing a relationship between primary care health personnel and key specialists, hospitals, and community-based organizations.

In the literature, similar to our study, analysis of the demographic characteristics predictive of non-urgent patients showed that age, sex, and arrival to the ED has found related to non-urgent ED visits $(3,13,14)$. The fact that non-urgent patients were younger than urgent patients and significantly in the 18-44 age group was consistent with other studies in the literature $(1,5,13,19)$. The non-urgent visit rate was significantly higher in patients arriving with their means than patients who arrived with ambulances. This difference may be because ambulance patients are pre-evaluated before arrival. Whether the patient's medical condition is an emergency or not is evaluated both at initial request to the emergency call center and when the emergency ambulance team reaches the patient. Therefore, both occasions prevent nonurgent visits from approaching the ED. While patients do not pay any expense for diagnosis or treatment in urgent or very-urgent triage codes in the ED, they do pay a contribution fee for non-urgent visits. However, it is far from being a deterrent because the amount of the contribution payment is taken from green zone patients is very low (3-5 US dollars) (20). Otherwise, all primary care services are provided free of charge.

Along with publications that state that EDs are preferred even with costs concerns, this may not be the case for our study. The fact that the rate of recurrent admissions in patients with previous non-urgent visits was $14.8 \%$ also supports this theory. In addition, the data was not obtained from a national database, and it is unknown whether patients visited different EDs within the same year. Our study determined that there were patients with 13,16, even 20 non-urgent visits.

The high number of urgent and non-urgent visits in the first days of the week may be related to patients who cannot get an outpatient appointment immediately after the weekend are referred to the ED. As in another study conducted in Turkey, non-urgent visits were found significantly higher during working hours. The most common diagnostic codes recorded in non-urgent visits were pain, upper respiratory tract infection, soft tissue disorder affecting the person's quality of life (21). This kind of non-urgent visit may be related to the fact that EDs can be accessed quickly without waiting queues, yield rapid test results, and promptly provide service. Studies conducted using surveys or hospital records also support this theory $(1,5,21-23)$. In Samsun, the population number per physician of FHC was above the average for Turkey (Turkey average 3124 vs. Samsun 3266) (10). In the year following this study's data collection, the Ministry of Health of Turkey initiated an out-of-hours service in FHC to decrease non-urgent visits to EDs and outpatient clinics. In many studies, it was found that reasonable access to primary care 
providers such as GPs and continuity of care measured by seeing the same family doctor were essential factors in reducing non-emergency ED visits $(24,25)$. In the current health system, while it may seem that patients being unable to access immediate health service leads them to prefer EDs (23), many studies have shown that the level of service, working hours, and increased professionalism do not decrease the use of $\operatorname{EDs}(5,19,26-28)$.

Our study has some limitations. We did not have some basic data that could elucidate the cause-effect relationship because of being record-based research. The records of patients who visited the ED did not include essential data such as distance to hospital, number of visits, education level, and marital status. Even data was collected from a large district hospital, conducting the study in only one hospital might limit the generalizability of our findings.

\section{Conclusion}

Our findings may shed light on some factors contributing to unnecessary ED visits. Harmonization of various databases at primary level in terms of design and connectivity and integration with hospital information systems will contribute to the identification of problems and the generation of solutions. In the next step, establishing an integrated health care system can benefit in emergency care organizations and many health service areas in Turkey.

\section{Abbreviations}

ED: Emergency department

FHC: Family Health center

HPRC: Health Practice and Research Center

\section{Declarations}

Ethics approval and consent to participate: Ethics approval was received from the Ondokuz Mayis University Clinical Research Ethics Committee (KAEK: 1500). Written informed consent was not obtained from the patients since the study was conducted on hospital records and anonymous data.

Consent for publication: Not applicable.

Availability of data and materials: The data that support the findings of this study are available on request from the corresponding author, [CD]. The data are not publicly available due to restrictions their containing information that could compromise the privacy of research participants.

Competing interests: The authors declare that they have no competing interests. 
Funding: This research received no specific grant from any funding agency in the public, commercial, or not-for-profit sectors.

Author contribution: CD made a substantial contribution to the concept and design of the work, analyzed data and contributed to interpretation of data revised the article critically for important intellectual content. SDY analyzed of data, drafted the article. All authors read and approved the final manuscript.

Acknowledgements: The authors want to thank the staffs from Information Service Division for their help with data reports obtained from the Statistical Information System of Health Practice and Research Center of Ondokuz Mayis University.

\section{References}

1. Naouri D, Ranchon G, Vuagnat A, Schmidt J, El Khoury C, Yordanov Y. Factors associated with inappropriate use of emergency departments: findings from a cross-sectional national study in France. BMJ quality \& safety; 2019.

2. Morley C, Unwin M, Peterson GM, Stankovich J, Kinsman L. Emergency department crowding: a systematic review of causes, consequences and solutions. PloS one. 2018;13(8).

3. Al-Adwan O, Stanford J, Hamner M. Examining the utilization of medical scribes in a hospital emergency department environment. Procedia computer science. 2017;118:34-47.

4. Baier N, Geissler A, Bech M, Bernstein D, Cowling TE, Jackson T, et al. Emergency and urgent care systems in Australia, Denmark, England, France, Germany and the Netherlands-Analyzing organization, payment and reforms. Health Policy. 2019;123(1):1-10.

5. Morris T, Mason SM, Moulton C, O'Keeffe C. Calculating the proportion of avoidable attendances at UK emergency departments: analysis of the Royal College of Emergency Medicine's Sentinel Site Survey data. Emerg Med J. 2018;35(2):114-9.

6. CDC. National Hospital Ambulatory Medical Care Survey. Emergency department visits, by selected characteristics: United States, 2017. 2017(14.02.2020).

7. NHS. Hospital Accident and Emergency Activity 2018-19 London2019 [Available from: https://files.digital.nhs.uk/F5/ACF07A/AE1819_Annual_Summary.pdf.

8. Tırgıl A. Cost of Health Care and Utilization of Emergency Departments in Turkey. International Journal of Economic Studies. 2017;3(2):161-70.

9. Dündar C. Health-seeking behavior and medical facility choice in Samsun, Turkey. Health Policy. 2017;121(9):1015-9.

10. Ministry_of_Health. Health Statistics Yearbook 2017. Ankara: Kuban Matbaacılık Yayıncılık; 2017. Available from: https://dosyasb.saglik.gov.tr/Eklenti/30148,ingilizcesiydijiv1pdf.pdf?0.

11. Ministry_of_Health. Kamu Hastaneleri Istatistik Yıllıgı 2017 (in Turkish) 2018 [Available from: https://dosyamerkez.saglik.gov.tr/Eklenti/21853,kamu-hastaneleri-istatistik-raporu-2017pdf.pdf?0. 
12. WHO. Integrated Care Models: An Overview. Copenhagen: World Health Organization 2016 [Available from: http://www.euro.who.int/_data/assets/pdf_file/0005/322475/Integrated-care-modelsoverview.pdf.

13. O'Keeffe C, Mason S, Jacques R, Nicholl J. Characterising non-urgent users of the emergency department (ED): a retrospective analysis of routine ED data. PLoS One. 2018;13(2).

14. Leporatti L, Ameri M, Trinchero C, Orcamo P, Montefiori M. Targeting frequent users of emergency departments: Prominent risk factors and policy implications. Health Policy. 2016;120(5):462-70.

15. Akkan C, Karadayi MA, Ekinci Y, Ülengin F, Uray N, Karaosmanoğlu E. Effıciency analysis of emergency departments in metropolitan areas. Socio-Economic Planning Sciences. 2020;69:100679.

16. Lynch B, Fitzgerald AP, Corcoran P, Buckley C, Healy O, Browne J. Drivers of potentially avoidable emergency admissions in Ireland: an ecological analysis. BMJ Qual Saf. 2019;28(6):438-48.

17. Akman M, Sakarya S, Sargın M, Ünlüoğlu İ, Eğici MT, Boerma WG, et al. Changes in primary care provision in Turkey: A comparison of 1993 and 2012. Health Policy. 2017;121(2):197-206.

18. Sumer S, Shear J, Yener AL. Building an Improved Primary Health Care System in Turkey through Care Integration. The World Bank; 2019.

19. Oh HC, Chow WL, GDFM YG, Tiah L, Goh SH, Mohan T. Factors associated with inappropriate attendances at the emergency department of a tertiary hospital in Singapore. Singapore medical journal. 2019.

20. Ada D, Unal B. The Effect of The Primary Care Services on The Intensity of Emergency Care Admissions to Public Hospitals in Turkey: An Ecological Study. Journal of Basic Clinical Health Sciences. 2018;2(3):82-8.

21. Idil H, Kilic TY, Toker I, Turan KD, Yesilaras M. Non-urgent adult patients in the emergency department: Causes and patient characteristics. Turkish Journal of emergency medicine. 2018;18(2):71-4.

22. Şimşek P, Gürsoy A. Turkish health care providers' views on inappropriate use of emergency department: Who, when and why? International emergency nursing. 2016;27:31 - 6 .

23. Green E, Shaw SE, Harris T. 'They shouldn't be coming to the ED, should they?'A qualitative study of why patients with palliative care needs present to the emergency department. BMJ supportive palliative care. 2019;9(4):e29-e.

24. Ranstad K, Midlöv P, Halling A. Active listing and more consultations in primary care are associated with reduced hospitalisation in a Swedish population. BMC Health Serv Res. 2018;18(1):101.

25. Wong $\mathrm{CY}$, Hall J. Does patients' experience of general practice affect the use of emergency departments? Evidence from Australia. Health Policy. 2018;122(2):126-33.

26. Posocco A, Scapinello MP, De Ronch I, Castrogiovanni F, Lollo G, Sergi G, et al. Role of out of hours primary care service in limiting inappropriate access to emergency department. Intern Emerg Med. 2018;13(4):549-55.

27. Dolton P, Pathania V. Can increased primary care access reduce demand for emergency care? Evidence from England's 7-day GP opening. Journal of Health Economics. 2016;49:193-208. 
28. Cowling TE, Majeed A, Harris MJ. Patient experience of general practice and use of emergency hospital services in England: regression analysis of national cross-sectional time series data. BMJ Qual Saf. 2018;27(8):643-54. 